() OPEN ACCESS

\title{
Moral motivation regarding dementia risk testing among affected persons in Germany and Israel
}

\author{
Zümrüt Alpinar-Sencan, ${ }^{1}$ Silke Schicktanz 지, ${ }^{1}$ Natalie Ulitsa, ${ }^{2}$ Daphna Shefet, ${ }^{3}$ \\ Perla Werner ${ }^{2}$
}

- Additional supplemental material is published online only. To view, please visit the journal online (http://dx.doi. org/10.1136/medethics-2020106990)

${ }^{1}$ Department for Medical Ethics and History of Medicine, University Medical Center Göttingen, Göttingen, Niedersachsen, Germany ${ }^{2}$ Department of Community Mental Health, University of Haifa, Haifa, Israel ${ }^{3}$ Shalvata Mental Health Care Center, Faculty of Medicine, Tel Aviv University, Tel Aviv, Israel

\section{Correspondence to}

Professor Silke Schicktanz, Department for Medical Ethics and History of Medicine, University Medical Center Göttingen, 37073 Gottingen, Niedersachsen, Germany; silke.schicktanz@medizin.unigoettingen.de

ZA-S and SiS are joint first authors.

Received 9 October 2020 Accepted 2 July 2021

\section{ABSTRACT}

Recent advances in biomarkers may soon make it possible to identify persons at high risk for late-onset Alzheimer's disease at a presymptomatic (preclinical) stage. Popular demand for testing is increasing despite the lack of cure and effective prevention options and despite uncertainties regarding the predictive value of biomarker tests. This underscores the relevance of the ethical, cultural and social implications of predictive testing and the need to advance the bioethical debate beyond considerations of clinical consequences. Our qualitative study included three groups of affected persons: People with mild neurocognitive disorder, their relatives and family caregivers of people with dementia. We explored their moral motivations regarding predictive, biomarker-based testing and preclinical diagnostics. We interviewed affected individuals in Germany and Israel ( $N=88$; 44 participants in each country). Transcripts of 12 focus groups and 12 semistructured interviews were content analysed with a focus on the moral motivations of affected persons in their justification of why they accept or reject predictive testing and early diagnosis. We grouped the underlying aspects of moral motivation into four ethical categories: beneficence as a form of personal utility focusing on well-being, the ties of responsibility linking families and their individual members, the importance of selfdetermination by later life planning and notions of a good life. In general, cultural parallels among these motives were very obvious. Cultural variation occurred mainly in openness to suicide, scepticism about test validity and emphasis on personal autonomy. The study underscores the importance of counselling for lifeplanning issues and of informing test candidates about problems with test validity and about the ambiguity of test results.

\section{INTRODUCTION}

Would you use a test that predicts your likelihood of developing Alzheimer's disease (AD) in the next 10 years? This question, for most still hypothetical and divisive (see, for example, ref. ${ }^{1}$ ), may soon become personally relevant for everyone. ${ }^{23}$ Over the past 2 years, a number of researchers and companies worldwide have announced the development of inexpensive, non-invasive blood tests for the prediction of $\mathrm{AD}$, the most common cause of dementia. Also, recent advances in predictive medicine and biological markers may soon make it possible to identify persons at high risk of lateonset $\mathrm{AD}$ through the detection of physiological changes during the earliest, presymptomatic (preclinical) stage of $\mathrm{AD}$, when the distinction between diagnosis and prediction is blurry. ${ }^{4}$ Nonetheless, the lack of cure and effective prevention options, the psychological burden of knowing one's risk as well as uncertainties regarding the predictive value of biomarker tests, ${ }^{6}$ challenge the desirability of predictive tests. ${ }^{7}$

Although the use of biomarkers is not yet recommended for clinical contexts, ${ }^{8} 9$ media reports can trigger public interest ${ }^{1011}$ and requests for testing and the willingness to pay out of pocket are increasing. A survey of German experts showed that biomarkers have made inroads into clinical practice in German hospitals and memory clinics, ${ }^{12}$ where they are being used in the absence of comprehensive counselling guidelines. ${ }^{13}$ However, a qualitative study conducted with 14 Israeli experts revealed a different picture. All experts stated that biomarkers are not used in clinical practice and recommended their use only in research contexts. ${ }^{14}$

These findings generate a question that has been debated in the field of gene-based predictive testing: whether, in the absence of any 'clinical utility' of testing, other moral reasons including especially 'personal utility' justify testing.

Specifically, in the area of dementia, Bunnik et $a l^{1516}$ question the moral acceptability of predictive tests because current tests offer low predictive validity for specific individuals. They stress that personal utility is served only if test information is of high enough quality to 'reasonably be used for decisions, actions or self-understanding which are personal in nature' $\left({ }^{16}\right.$ p. 324).

While the differentiation between clinical and personal utility is helpful, focusing on utility alone might tie our thinking too closely to utilitarian approaches. The actual spectrum of relevant moral motivations may be much wider. By moral motivations, we refer to basic moral attitudes or opinions that influence and guide how people feel and act. A focus on moral motivation seems to us appropriate when asking people how they would act or assess particular situations. However, we do not state that motivations are always considered judgements or reliable, stable attitudes. Moreover, they might depend on the meanings imputed to specific illnesses in specific cultures.

The high prevalence of dementia ${ }^{17} 18$ and the popularisation of the topic in the media ${ }^{19} 20$ increase the relevance of considering not only the clinical consequences of such predictive tests but also their wider ethical, social and cultural implications. We share the scepticism stemming from problems with the clinical validity of $\mathrm{AD}$ 
Table 1 Overview of participants' sociodemographics

\begin{tabular}{|c|c|c|c|c|c|c|}
\hline & \multicolumn{2}{|c|}{ Family caregivers (FC) } & \multicolumn{2}{|c|}{$\begin{array}{l}\text { Relatives of people with mild neurocognitive } \\
\text { disorder (R_MND) }\end{array}$} & \multicolumn{2}{|c|}{$\begin{array}{l}\text { People with mild neurocognitive disorder } \\
\qquad \text { (P_MND) }\end{array}$} \\
\hline & Germany & Israel & Germany & Israel & Germany & Israel \\
\hline Type of data collection & $\begin{array}{l}5 \mathrm{FG} \\
\text { (together with } \mathrm{R}_{-} \mathrm{MND} \text { ) }\end{array}$ & $3 \mathrm{FG}$ & $\begin{array}{l}5 \mathrm{FG} \\
\text { (together with FC) }\end{array}$ & $1 \mathrm{FG}$ & $\begin{array}{l}12 \text { (face-to-face } \\
\text { interviews) }\end{array}$ & $3 \mathrm{FG}$ \\
\hline Number of participants & 20 & 20 & 12 & 8 & 12 & 16 \\
\hline \multicolumn{7}{|l|}{ Gender } \\
\hline Female & 16 & 15 & 11 & 5 & 5 & 8 \\
\hline Male & 4 & 5 & 1 & 3 & 7 & 8 \\
\hline \multicolumn{7}{|l|}{ Age (years) } \\
\hline $18-25$ & 0 & 0 & 0 & 0 & 0 & 0 \\
\hline $26-35$ & 3 & 0 & 0 & 0 & 0 & 0 \\
\hline $36-50$ & 1 & 1 & 1 & 1 & 0 & 0 \\
\hline $51-70$ & 12 & 8 & 3 & 5 & 5 & 0 \\
\hline 71 and above & 2 & 11 & 2 & 2 & 7 & 16 \\
\hline No information & 2 & 0 & 6 & 0 & 0 & 0 \\
\hline \multicolumn{7}{|l|}{ Marital status } \\
\hline Married & 10 & 16 & 9 & 4 & 6 & 9 \\
\hline Partnership & 1 & 0 & 0 & 0 & 1 & 0 \\
\hline Single & 4 & 1 & 0 & 1 & 1 & 0 \\
\hline Divorced & 2 & 2 & 1 & 2 & 0 & 0 \\
\hline Widow/widower & 1 & 1 & 0 & 1 & 4 & 7 \\
\hline No information & 2 & 0 & 2 & 0 & 0 & 0 \\
\hline \multicolumn{7}{|l|}{ Years of education } \\
\hline $0-9$ & 2 & 1 & 1 & 0 & 3 & 0 \\
\hline $10-12$ & 7 & 8 & 3 & 1 & 7 & 5 \\
\hline $13+$ & 9 & 11 & 2 & 7 & 2 & 11 \\
\hline No information & 2 & 0 & 6 & 0 & 0 & 0 \\
\hline
\end{tabular}

$\mathrm{FG}$, focus groups.

biomarker tests. Yet, an examination of the wide spectrum of moral motivations underlying individuals' desire to get tested anyway is necessary for advancing a deeper bioethical debate. There is a research gap on what healthy citizens and affected persons think about AD biomarker tests. Such perspectives and attitudes of lay persons ${ }^{i}$ should be included in these debates to augment expert opinion (see refs. ${ }^{21} 22$ ). We employ empirical and participatory approaches here to help identify the expectations and preferences of those affected directly or indirectly and to fill in this research gap.

The main goal of the larger study was to explore empirically affected persons' (ie, people with mild neurocognitive disorder (MND), their relatives and family caregivers (FC) of people with dementia) attitudes towards dementia risk information $^{\text {ii }}$ and to illuminate their counselling needs. For this article, we focus on individuals' moral motivations for justifying why they are either for or against predictive testing and early diagnosis.

A secondary goal of the study is an exploration of the question of whether differences in AD testing attitudes vary on a cultural level. This study therefore includes participants from two countries, Germany and Israel. Existing studies of various bioethical dilemmas, regarding reproductive medicine and

${ }^{\mathrm{i}}$ By lay persons, we refer to anybody who is not a professional expert on the topic at quest. In that sense, lay persons can include persons with a high academic background.

ii This formulation is meant to include both predictive biomarker-based testing and biomarker-based forms of very early diagnosis in preclinical stages of Alzheimer's disease, when the difference between prediction and diagnosis is unclear. genetic testing for late-onset diseases such as cancer and endof-life decisions $\left(\mathrm{see}^{23}\right)$, give grounds to believe that patterns of moral motivation can be influenced by the cultural values embedded in these two national contexts. It is not currently known whether cultural patterns of moral motivation like these are visible also in the case of AD prediction. Germany and Israel are also attractive for cultural comparison because in both countries public interest in prediction and early diagnosis of AD is currently high and both countries have formulated a national dementia strategy. ${ }^{24} 25$ The goal of the GermanyIsrael comparison in this study is modest: we seek only to find out if any clear differences exist, not to explain them.

\section{METHODS}

\section{Study design}

This particular study is part of a larger cross-sectional, qualitative study aimed at exploring how various stakeholders' moral and psychosocial attitudes regarding early diagnosis of dementia are embedded in social and cultural contexts in Germany and Israel. We used focus groups (FG) and face-toface, semistructured interviews (see online supplemental material 1 which provides the questionnaire) with affected persons (44 participants in Germany and 44 in Israel) (see table 1).

\section{Recruitment and sample composition}

Purposive sampling was used in both countries. In Israel, people with MND (P_MND) and their relatives (R_MND) were recruited from a mental health medical centre in the central part of Israel. FC of people with dementia were recruited through support groups 
organised by the Israeli Alzheimer's Association in three Israeli cities. In Germany, flyers and posters were distributed to memory clinics and patients' organisations, an advertisement was placed in regional newspapers in two mid-sized cities and memory-clinic patients who had declared an interest in taking part in scientific studies were contacted. As is common in cross-national qualitative studies, ${ }^{26}$ the countries' cultural and institutional differences made different recruiting methods necessary. Participant selection was made also with the goal of increasing the sociodemographic diversity of the sample (see table 1 for sociodemographic information).

In Israel, seven FG were conducted from June to October 2018: three with FC, one with R_MND and three with P_MND. In Germany, five FG were conducted with FC together with R_MND. These FG took place in four German cities in central and western Germany from June 2017 to February 2018. Additionally, 12 interviews were conducted with P MND from August to December 2017 at their homes to reduce for them the risk of potential stress by participating in a FG setting. Following the request of some participants, five interviews were held with the participation of their family members $(\mathrm{N}=5)$, whose answers were included in the study. Only in Germany was diagnosis information self-reported. In Israel, diagnosis was based on clinical data information.

FG and face-to-face interviews were conducted using a semistructured guideline developed jointly by the research teams in both countries in English and later translated into German and Hebrew. Translations focused on ensuring identical meanings, not identical wording. Interview guidelines were structured around topics related to (a) participants' experiences and assessments of prediction and early diagnosis of dementia, (b) assessments of situations in which predictive test results were disclosed, (c) the impact of this information on individuals and family life and (d) assessments of advance directives for future care. In both countries, FG were moderated by research team members with experience in qualitative research and lasted $90-120 \mathrm{~min}$. In Germany, all interviews were conducted by the same researcher and lasted $25-45$ min. FG discussions and interviews were audio recorded and then transcribed verbatim, using pseudonyms. ${ }^{27}$ All materials relevant for the final analysis were translated into English.

\section{Data analysis}

Analysis followed the six phases of thematic analysis as outlined by Braun and Clarke. ${ }^{28}$ We began by having transcribed verbatim FG discussions and interviews. At the beginning, by referring to the larger study's aims, we generated the initial codes, which were extracted as key topics from relevant overview work on ethics of dementia prediction. ${ }^{12}{ }^{29-32}$ However, our initial coding was not enough to identify study participants' basic moral attitudes (ie, moral motivations) towards being for or against predictive testing and early diagnosis. Therefore, in a deductive way of thematic analysis, as described by Braun and Clarke, ${ }^{28}$ we generated further codes and organised our data into meaningful groups. These codes were discussed within and across research groups in both countries until consensus over the code structure was reached. In a next step, we sorted the different codes into potential themes. We identified the following main overarching themes: 'beneficence', 'responsibility', 'self-determination' and 'visions of a good life' and subthemes within them (see online supplemental material table 2). These categories are neither based on one coherent ethical theory nor do they match perfectly to the four common bioethical principles suggested by Beauchamp and Childress. ${ }^{33}$ Still, our classification into common ethical categories serves as a 'translation' between lay morality and the ethics expert discourse. By this, we want to inform the analysis of how such moral reflection occurs in everyday life (see refs. ${ }^{34-36}$ ). Our analysis relied on organising sections of the data into recurrent common themes raised by participants in both countries. Then, following the next phase of thematic analysis outlined by Braun and Clarke, ${ }^{28}$ we reviewed (by checking if the coded data extracts form a coherent pattern) and refined (by checking if themes reflect the meanings evident in data set) our themes. Then, in the next phase, we generated definitions for each theme (see below for how each theme is defined) and refined the specifics for each theme to ensure that they do not overlap. The final phase included the identification of prototypical statements within the material. Due to space limitation, we summarise relevant statements also in the table (see online supplemental material table 2).

As suggested in qualitative methodology, ${ }^{37}$ in order to increase the validity of the data and attain a more comprehensive understanding of the topic under study, we relied on the two types of triangulation. First, we conducted methods triangulation by using two qualitative methods-personal interviews and focus groups. Second, we conducted data triangulation by examining different stakeholders' group and exploring different perspectives of this complex issue. Finally, we conducted investigator triangulation by separately and parallelly coding the translated material of both countries and then by crosschecking and verifying the interpretation of the data.

\section{RESULTS}

Study participants in both countries were about evenly split in their positions for or against predictive dementia testing. Very few were openly ambivalent. Country-level differences are mentioned when pronounced, but the similarities in arguing along moral motivation were dominant and a main focus of our analysis. The reasoning underlying their positions can be grouped into ethical categories as follows.

\section{Beneficence}

In ethical theory, beneficence includes all norms, dispositions and actions with the goal of benefiting or promoting the good of other persons. Considerations of the beneficence in the health context of an action do not only include assessments of promoting physical or psychological well-being but also the avoidance or reduction of negative impacts on the good, such as reducing risks (possible future harm) or costs (harm) $\left({ }^{33}\right.$ see). Avoiding harm refers to the ethical principle non-maleficence as well. However, we define these issues into 'being beneficial' in the context of risk reduction and prevention: It is based on doing actively something (eg, changing life style), while nonmaleficence can be understood as 'non-acting', namely omitting an action that might harm. In general, personal utility is understood in a broader sense and not only health-related well-being but it also includes fulfilling pleasure or curiosity (as for some people a motivation to direct-to-consumer genetic testing).

In both countries, participants in all stakeholder groups mentioned potential long-term benefits of prospective risk assessment, including, for example, starting early with medication and the modification of risk factors through diet and cognitive training. Thus, their trust in the possibility of reducing the risk of developing dementia symptoms and their trust in medical science underlay their attitude that predictive information is beneficial:

There is no cure, but there are things (medications) that can slow (the progress) down. (Male, R_MND, Israeli) 
In contrast, those who had less faith in medical science or had negative views regarding recent advances in medical technology (noting, for example, the lack of effective, diseasemodifying treatments) or who expressed doubts regarding the reliability or credibility of predictive testing questioned also the benefit of prospective risk information:

(...) (I)f there is nothing you can do and I simply rush towards such a disease, then I, of course, would prefer not to know anything about it. (...). (Female, FC, German)

Especially, German participants voiced concerns about test validity and reliability more frequently compared with Israeli counterparts. This scepticism corresponded also to mistrust in physicians' competence to diagnose the disease and to concerns about the lack of clear diagnostic criteria. Some participants in both countries said they would make no substantial lifestyle changes based on uncertain information.

\section{Prospective responsibility}

Generally, 'responsibility' refers to making judgements about whether moral agents should be held accountable for their behaviour, their actions and their actions' outcomes in relation to a moral object. It also has a time dimension ${ }^{38}$ : retrospective responsibility means being responsible for some past action, while prospective responsibility includes hypothetical outcomes regarding future events in the short or long term. Here, we identified mainly future-oriented responsibility. Responsibility is understood as a metaethical category, ${ }^{38}$ which can address different moral subjects and different moral objects. Therefore, we differentiate in our analysis whether the family is addressed as a moral subject (eg, the family is responsible for a patient) or whether the patient feels responsible for the family.

Some participants in both countries had positive attitudes about prospective risk information specifically because they held this information to be relevant for responsibility taking in terms of considering concrete options for care and organising financial issues. The underlying ethical category is responsibility for one's family. Thus, their willingness to know risk information was tied to a felt moral obligation to avoid burdening family members:

(...) I have a son. I don't want to burden him. (...) I want to prepare things, to set aside funds, to prepare all kinds of things. (Female, FC, Israeli)

Another underlying ethical category was the family's responsibility for the affected person. Some participants articulated an expectation that the family is morally obligated to take care of a family member in an advanced stage of dementia. For example, on the subject of advance directives, some saw no need to plan ahead, in the expectation that family members would make all decisions if necessary. This attitude was closely tied to trust in (and commitment to) one's family and the perception that the family is trustworthy and capable of making good decisions. This sense of responsibility included assumptions about the family's readiness to take care of the directly affected person and was emphasised more by the Israeli participants. Persons who expect to receive help from family if needed also had positive attitudes towards predictive testing and early diagnosis of dementia:

(...) I think my children are so devoted that they know exactly what to do, let's say if something happens to me. (...) I trust them! They trust me now, I'll trust them later! (Female, FC, Israeli)
Finally, obtaining risk information or an early diagnosis was seen by participants in both countries as an opportunity to take responsibility for their own health. The underlying ethical category here is self-responsibility. They wanted to know in advance of any risk to their cognitive health. The absence of a cure and uncertainty regarding the progression of symptom severity were for them of little importance. Predictive information was seen as an opportunity to take action to slow the progress of the disease:

(...) I think it was good that I had the test. (...) Because I think that everyone should do something for her health or illness. (Female, P_MND, German)

\section{Self-determination}

This ethical category signifies being autonomous in one's decisions, either by exercising personal control or having one's wishes honoured should one become mentally incompetent due to an illness. ${ }^{33}$ In liberal ethics, self-determination gains priority over other values. However, in the context of dementia, self-determination is often discussed as diminished or limited due to cognitive decline.

For many participants, dementia was strongly associated with loss of control. Hence, some appreciated the idea of predictive testing because they see in it an opportunity to strengthen their control over their own lives through preparation for future needs. For them, self-determination is a relevant moral motivation for testing irrespective of the practical potential for realising personal utility. Participants in all groups expressed a wish to make and carry out their own life decisions, especially those concerning future care, including advance directives. However, German participants articulated more intensely the importance of autonomy and the fear of losing control:

(...) (F)or me self-rule or self-determination is the highest good of an individual (...) and nobody has the right to revise the decision that was made out of free will. (...). (Male, FC, German)

Some German participants saw another advantage of early detection in the opportunity to plan suicide or active euthanasia:

(...) (I)f you indeed have the probability (...) you can think more clearly about it with a certain distance. To organize things - if there is a pill that can end one's life immediately (...). (A)t least, I have the option to think about it. (Female, FC, German)

These individuals expressed a strong desire to control their life course and believed dementia is associated with a loss of control. Among Israelis, only a few participants in the P_MND group made this connection.

\section{Vision of a good life}

Individual perspectives on what enhances life quality and how one should live constitute a person's personal vision of a good life. As Taylor ${ }^{39}$ put it, there is a connection between our vision of a good life (what way of life is worthwhile, admirable or of value) and our sense of our self, our identity. Because, identity can be defined by what is important to an individual, what is central to the person's well-being and what constitutes their notions of a full life well lived. Cultural narratives and social ideals, formed by religion or cultural history, also inform visions of good life.

The data show differences in participants' visions of a good life. Participants' expectation of the severity of symptoms 
affected their desire to acquire risk information. Some participants in the FC and R_MND groups in both countries believed that knowing their dementia risk would lower their quality of life. Israeli participants more intensely stressed that risk information could lead to negative associations with ageing, anxiety, stress and/or depression:

As everything I haven't got, which I'm diagnosed as possible, or, let me say, that I might fall ill with. That's a strain for me! (...). (Female, R_MND, German)

Few participants in the FC and R_MND groups in either country held the contrary opinion that risk information or early diagnosis could help to improve one's life, for example, by providing an early opportunity to integrate the illness into one's understanding of self:

(...) (If) I know it (predictive information), great, I will plan, enjoy life, travel, I will enjoy it and seize it till the end... (Female, R_ MND, Israeli)

Israeli participants often used self-characterisations (as hedonistic, optimistic, pessimistic or realistic) to explain their position on dementia prediction. For example, if the person was optimistic, she would accept the situation calmly and strive for living in the moment:

Here the individual's personality really enters the picture. Someone might want to fight it (...). But if she's the type who tends to depression, it's awful. (Female, FC, Israeli)

\section{DISCUSSION}

The study demonstrates that study participants' attitudes towards early diagnosis and prediction can be classified along ethical categories, which are central also for the applied ethics discourse. Notably, there was no strong tendency favouring predictive testing or early diagnosis. This stands in contrast to studies conducted in the UK and the Netherlands that found predominantly positive attitudes. ${ }^{40-42}$ However, these studies had different sampling strategies (ie, the participants were recruited from particular cohort studies and working groups), which might have led to different trends in opinion. Interestingly, our study found that predictive testing and early diagnosis of dementia were assessed positively when perceived as providing an opportunity to plan later life (eg, making practical arrangements) and to help the affected persons and their families make future decisions (eg, accessing earlier assistance from health and social services), irrespective of the paucity of prevention and treatment options. These findings show that attitudes towards predictive testing are related to perceived personal utility of the information. This corresponds to similar studies, in which, for instance, making informed decisions regarding care (eg, starting early with medication, changing life style, making practical arrangements) were defined as perceived personal utility of risk information. ${ }^{40-42}$ Likewise, a study conducted in the USA among older adults showed that knowing one's hypothetical risk of developing $\mathrm{AD}$ was seen as an opportunity to engage in life planning, for example, in the form of advance directives, ${ }^{43}$ which is also perceived as beneficial to the person.

The emergence of non-genetic, predictive biomarker testing for late-onset dementia gives occasion to reflect on parallels to the debate on lay attitudes about genetic testing and for a more detailed understanding of 'personal utility'. Our study suggests not to overload the term 'personal utility' to make a claim against focusing only on clinical utility.

According to Bunnik et al, ${ }^{15}$ 'personal utility' signifies the extent to which a biomarker test has the potential to effect positive changes on a personal level in some other, medically irrelevant way. Clinical utility means 'the extent to which a biomarker test will affect clinical management and improve the individual's health' ( ${ }^{15}$ p. 831$)$. In the context of directto-customer genomic tests, Chung and $\mathrm{Ng}^{44}$ argue even for a very broad understanding of personal utility: if a consumer wants to be informed about her biological traits, these tests have personal utility for her because they satisfy her interest (ie, taking the tests) and her desire to know (ie, getting the results). The medical-ethical principle of beneficence, that it is to justify acts because they promote the physical or psychological well-being of a person, is accordingly linked to utility. The 'personal' part in utility, however, stresses subjective interpretations and can even go beyond clinical understanding of health-related well-being.

Overall, from our explorative findings we draw four lines of conclusion. First of all, we believe it is important not to narrow down the discussion to clinical versus personal utility in bioethics. Experts, who struggle to acknowledge the legitimacy of subjective interests due to paternalistic assumptions about what is good for the patient, should understand that there are various moral motivations that go beyond personal utility. Thus, motives that are gathered under the category of 'beneficence' refer well to the expectations to improve the physical or psychological well-being. Moreover, we identified several ideas of responsibility between individuals and the family that shape strongly the attitudes towards such testing beyond personal utility. The desire for selfdetermination to plan later life and to make informed decisions goes also beyond personal utility notions. Finally, the visions of a good life linked to personality have also important implications too.

Second, our study revealed scepticism about the diagnostic value of testing. Non-genetic biomarker tests for AD still suffer from low predictive accuracy; there is still no certainty whether or when an asymptomatic person with an elevated biomarker level might later develop significant AD symptoms. ${ }^{45}$ When people understand that predictive test validity is low, their interest in getting tested is much reduced. ${ }^{42}$ Therefore, clinicians should ensure that tested persons understand the limits to the validity and certainty of their personal risk test results. They should also include information about life-planning strategies and other relevant implications. To date, empirically evaluated clinical communication recommendations do not exist. Hence, we recommend that this gap should be soon addressed to support patient-oriented decision-making.

Third, we propose that the aspects of moral motivation explored here can serve also as starting points for public and familial deliberations concerning the implications that might result from receiving information about personal higher risk of developing $\mathrm{AD}$ symptoms. Our study found that affected persons have specific assumptions about their respective areas of responsibility. If these assumptions are not reciprocal, families may be headed for conflict when a family member develops dementia symptoms.

Finally, our cross-cultural study on moral motivation allows hypothesising that various similarities among German and Israeli affected group exist. In few topics, previous patterns of cultural variation in medical ethics across Germany and Israel also occurred, for example, the greater openness of German participants to 
suicide. We also found other differences, such as the greater scepticism about test validity and the greater emphasis on personal autonomy among German study participants. In contrast, Israeli participants put emphasis on trust in one's family and underlined the negative feelings triggered by risk information. As our focus here was to search for similarities, we recommend larger crosscultural comparisons to shed light on differences on nationalcultural patterns.

\section{LIMITATIONS}

The use of qualitative methods with a small sample is subject to limitations related to the generalisability of the results for the broader population. More women than men participated as FC and R_MND in both countries, which might be a reflection of the caregiving characteristics in informal caregiving. ${ }^{46}$

Acknowledgements The authors would like to thank Leopold Lohmeyer, cand. med., for conducting the face-to-face interviews in Germany. The authors would also like to express their gratitude to Scott Stock Gissendanner for his help on the final language revision.

Contributors SiS conceptualised the research questions and general ideas, designed the study, supervised data collection and data analysis in Germany and revised written drafts. ZAS conducted the underlying research and the data analysis in Germany and wrote the first draft. ZAS and SiS share the first authorship as they contributed equally to subsequent drafts. NU collected the data and conducted data analysis in Israel. DS assisted in the data collection in Israel. PW designed the study, supervised the data collection and data analyses in Israel and assisted with writing the article. All authors approved the final manuscript.

Funding This study was funded by a grant from the German-Israeli Foundation for Scientific Research and Development (grant number G-1413-119.4/2017) to SS and PW.

\section{Competing interests None declared.}

Patient consent for publication Not required.

Ethics approval The study's protocols were approved by the University Medical Centre Göttingen's Ethics Committee (Ref. Nr. 17/12/16) in Germany and by the University of Haifa's Ethics Committee (Ref. Nr. 384/17; 12/11/2017) in Israel.

Provenance and peer review Not commissioned; externally peer reviewed.

Data availability statement All data relevant to the study are included in the article or uploaded as supplementary information.

Supplemental material This content has been supplied by the author(s). It has not been vetted by BMJ Publishing Group Limited (BMJ) and may not have been peer-reviewed. Any opinions or recommendations discussed are solely those of the author(s) and are not endorsed by BMJ. BMJ disclaims all liability and responsibility arising from any reliance placed on the content. Where the content includes any translated material, BMJ does not warrant the accuracy and reliability of the translations (including but not limited to local regulations, clinical guidelines, terminology, drug names and drug dosages), and is not responsible for any error and/or omissions arising from translation and adaptation or otherwise.

Open access This is an open access article distributed in accordance with the Creative Commons Attribution Non Commercial (CC BY-NC 4.0) license, which permits others to distribute, remix, adapt, build upon this work non-commercially, and license their derivative works on different terms, provided the original work is properly cited, appropriate credit is given, any changes made indicated, and the use is non-commercial. See: http://creativecommons.org/licenses/by-nc/4.0/.

\section{ORCID iD}

Silke Schicktanz http://orcid.org/0000-0001-9627-752X

\section{REFERENCES}

1 AbbVie Healthcare Monitor. Attitudes towards Blood Test for Late-Onset Dementia. AbbVie Healthcare Monitor. Available: https://www.abbvie.de/content/dam/abbviedotcom/de/documents/maerz-2018-abbvie-health-care-monitor-altersdemenz.pdf? trackingSelection=Yes [Accessed 22 Jul 2020].

2 Rodriguez A. Blood test for beta amyloid may be used to predict alzheimer disease risk. Am J Manag Care, News Room, 2019. Available: https://www.ajmc.com/ newsroom/blood-test-for-beta-amyloid-may-be-used-to-predict-alzheimers-diseaserisk [Accessed 22 Jul 2020].

3 National Institutes of Health. New blood test method may predict Alzheimer's disease. NIH Research Matters, 2020. Available: https://www.nih.gov/news-events/nih- research-matters/new-blood-test-method-may-predict-alzheimers-disease [Accessed 22 Jul 2020].

4 Sperling RA, Aisen PS, Beckett LA, et al. Toward defining the preclinical stages of Alzheimer's disease: recommendations from the National Institute on AgingAlzheimer's association workgroups on diagnostic guidelines for Alzheimer's disease. Alzheimers Dement 2011;7(3):280-92.

5 Dubois B, Hampel H, Feldman HH, et al. Preclinical Alzheimer's disease: definition, natural history, and diagnostic criteria. Alzheimers Dement 2016;12(3):292-323.

6 Gauthier S, Leuzy A, Racine E, et al. Diagnosis and management of Alzheimer's disease: past, present and future ethical issues. Prog Neurobiol 2013;110:102-13.

7 Werner P, Karnieli-Miller O, Eidelman S. Current knowledge and future directions about the disclosure of dementia: a systematic review of the first decade of the $21 \mathrm{st}$ century. Alzheimers Dement 2013;9(2):e74-88.

8 Deuschl G, Maier W. "S3-Leitlinie 'Demenzen' Langversion." Deutsche Gesellschaft für Psychiatrie und Psychotherapie, Psychosomatik und Nervenheilkunde (DGPPN), Deutsche Gesellschaft für Neurologie (DGN). In: Zusammenarbeit MIT Der deutschen Alzheimer Gesellschaft, 2016. https://www.awmf.org/uploads/tx_szleitlinien/038013|_S3-Demenzen-2016-07.pdf

9 Jack CR, Bennett DA, Blennow K, et al. NIA-AA research framework: toward a biological definition of Alzheimer's disease. Alzheimers Dement 2018;14(4):535-62.

10 Kolata G. A blood test for alzheimer's? it's coming, scientists report: The New York Times, 2019. Available: https://www.nytimes.com/2019/08/01/health/alzheimersblood-test.html [Accessed 26 Mar 2020].

11 Rawlinson K. Alzheimer's blood test could predict onset up To 20 years in advance. The Guardian, 2019. Available: https://www.theguardian.com/society/2019/ aug/02/ alzheimers-test-predicts-onset-up-to-20-years-in-advance [Accessed 26 Mar 2020].

12 Schweda M, Kögel A, Bartels C, et al. Prediction and early detection of Alzheimer's dementia: professional disclosure practices and ethical attitudes. J Alzheimers Dis 2018;62(1):145-55.

13 Alpinar-Sencan Z, Schicktanz S. Addressing ethical challenges of disclosure in dementia prediction: limitations of current guidelines and suggestions to proceed. BMC Med Ethics 2020;21(1):33.

14 Ulitsa N, Werner P, Shefet D, et al. Early diagnosis of Alzheimer's disease and the use of biomarkers: The views of Israeli experts in the field. Gerontology and Geriatrics: J Aging Stud 2021;48(1):61-81.

15 Bunnik EM, Richard E, Milne R, et al. On the personal utility of Alzheimer's diseaserelated biomarker testing in the research context. J Med Ethics 2018;44(12):830-4.

16 Bunnik EM, Janssens ACJW, Schermer MHN. Personal utility in genomic testing: is there such a thing? J Med Ethics 2015:41(4):322-6.

17 World Health Organization [website]. Dementia: number of people affected to triple in next 30 years, 2017. Available: https://www.who.int/news-room/detail/07-122017-dementia-number-of-people-affected-to-triple-in-next-30-years [Accessed 22 Jul 2020].

18 World Health Organization. Dementia, 2019. Available: https://www.who.int/newsroom/fact-sheets/detail/dementia [Accessed 22 Jul 2020].

19 Swinnen A, Schweda M. Popularizing dementia: public expressions and representations of Forgetfulness. Bielefeld: Transcript Verlag, 2015.

20 Werner P, Vermeulen P, Van Gorp B. From history to intervention: a Socio-Cultural analysis of dementia stigma. Dementia and Society, Cambridge Press, 2021.

21 Schicktanz S, Schweda M, Wynne B. The ethics of 'public understanding of ethics'-why and how bioethics expertise should include public and patients' voices. Med Health Care Philos 2012;15(2):129-39.

22 Involve, 2020. Available: https://www.invo.org.uk/ [Accessed 22 Jul 2020].

23 Raz A, Schicktanz S. Comparative empirical bioethics: dilemmas of genetic testing and euthanasia in Israel and Germany. Springer, 2016. ISBN: 978-3-319-32733-4.

24 Federal Ministry of Education and Research. Kabinett Beschließt Nationale Demenzstrategie, 2020. Available: https://www.bmbf.de/de/kabinett-beschliesstnationale-demenzstrategie-11963.html [Accessed 22 Jul 2020].

25 Brodsky J, Bentur N, Laron M. Addressing Alzheimer's and other types of dementia: Israeli national strategy. Jerusalem: Myers-JDC-Brookdale Institute and Ministry of Health, 2013.

26 Chapple A, Ziebland S. Methodological and practical issues in cross-national qualitative research: lessons from the literature and a comparative study of the experiences of people receiving a diagnosis of cancer. Qual Health Res 2018;28(5):789-99.

27 Metschke R, Wellbrock R. Datenschutz in Wissenschaft und Forschung. 3 edn. Berlin: Druckerei Conrad GmbH, 2002.

28 Braun V, Clarke V. Using thematic analysis in psychology. Qual Res Psychol 2006;3(2):77-101.

29 Low L-F, McGrath M, Swaffer K, et al. Communicating a diagnosis of dementia: a systematic mixed studies review of attitudes and practices of health practitioners. Dementia 2019;18(7-8):2856-905.

30 Nielsen TR, Svensson BH, Rohr G, et al. The process of disclosing a diagnosis of dementia and mild cognitive impairment: a national survey of specialist physicians in Denmark. Dementia 2020;19(3):547-59.

31 Hansen EC, Hughes C, Routley G, et al. General practitioners' experiences and understandings of diagnosing dementia: factors impacting on early diagnosis. Soc Sci Med 2008:67(11):1776-83.

32 Iliffe S, Manthorpe J, Eden A. Sooner or later? issues in the early diagnosis of dementia in general practice: a qualitative study. Fam Pract 2003;20(4):376-81.

33 Beauchamp TL, Childress JF. Principles of biomedical ethics. 6 edn. New York: Oxford University Press, 2009. 
34 Borry P, Schotsmans P, Dierickx K. What is the role of empirical research in bioethical reflection and decision-making? an ethical analysis. Med Health Care Philos $2004 ; 7(1): 41-53$.

35 van der Scheer L, Widdershoven G. Integrated empirical ethics: loss of normativity? Med Health Care Philos 2004;7(1):71-9.

36 Musschenga AW. Empirical ethics, context-sensitivity, and contextualism. J Med Philos 2005:30(5):467-90.

37 Carter N, Bryant-Lukosius D, DiCenso A, et al. The use of triangulation in qualitative research. Oncol Nurs Forum 2014;41(5):545-7.

38 Schicktanz S, Schweda M. The diversity of responsibility: the value of Explication and Pluralization. Med Stud 2012;3(3):131-45.

39 Taylor C. Sources of the self: the making of the modern identity. Cambridge, MA: Harvard University Press, 1989.

40 Vanderschaeghe G, Schaeverbeke J, Bruffaerts R, et al. Amnestic MCI patients' experiences after disclosure of their amyloid PET result in a research context. Alzheimers Res Ther 2017;9(1):1-16.
41 Vanderschaeghe G, Vandenberghe R, Dierickx K. Stakeholders' views on early diagnosis for Alzheimer's disease, clinical trial participation and amyloid PET disclosure: a focus group study. J Bioeth Inq 2019;16(1):45-59.

42 Milne R, Bunnik E, Diaz A, et al. Perspectives on communicating biomarker-based assessments of Alzheimer's disease to cognitively healthy individuals. J Alzheimers Dis 2018;62(2):487-98.

43 Sheffrin M, Stijacic Cenzer I, Steinman MA. Desire for predictive testing for Alzheimer's disease and impact on advance care planning: a cross-sectional study. Alzheimers Res Ther 2016;8(1).

44 Chung MWH, Ng JCF. Personal utility is inherent to direct-to-consumer genomic testing. J Med Ethics 2016;42(10):649-52.

45 Mozersky J, Sankar P, Harkins K, et al. Comprehension of an elevated amyloid positron emission tomography biomarker result by cognitively normal older adults. JAMA Neurol 2018;75(1):44-50.

46 Navaie-Waliser M, Spriggs A, Feldman PH. Informal caregiving: differential experiences by gender. Med Care 2002;40(12):1249-59. 